\title{
Characteristics of Phonocardiography Waveforms that Influence Automatic Feature Recognition
}

\author{
Scott Stainton $^{1}$, Charalampos Tsimenidis ${ }^{1}$, Alan Murray ${ }^{1,2}$ \\ ${ }^{1}$ School of Electrical and Electronic Engineering and \\ ${ }^{2}$ Faculty of Medical Sciences, \\ Newcastle University, Newcastle upon Tyne, UK
}

\begin{abstract}
Phonocardiography is a very common diagnostic test, especially for the study of heart valve function. However, this test is still almost entirely manual using a stethoscope because of the difficulties in analysing waveforms with excessive acoustic noise, and with subtle clinical characteristics requiring good hearing for detection. The PhysioNet phonocardiography data were analysed to assess the characteristics that related to successful detection of normal or abnormal characteristics.

After processing to reduce the effect of noise, the mean signal level in comparison to the processed peak valve sounds was $45 \pm 15 \%$. There was a tendency for the signal level to be higher in the abnormal recordings, but this was significant only in one of the five PhysioNet databases, by $8 \%(p=0.002)$. It was noted that one database had significantly higher noise levels than the other four.

Autocorrelation was used to analyse the processed waveforms, with successful automated detection in 58\% of recordings of peaks associated with both the first and second heart sounds. This was more effective in the normal group with a $5 \%(p=0.01)$ greater success rate than in the abnormal group. For all the data analysed, there was only one small significant difference between the normal and abnormal groups, and so combined data are reported. The autocorrelation time to the subsequent heart beat provided the heart beat interval, and was $0.83 \pm 0.19 \mathrm{~s}$ (mean $\pm S D$ ). The first and second heart sounds relative to the heart beat interval had a timing of $37 \pm 6 \%$ and $65 \pm 6 \%$, and an amplitude $43 \pm 21 \%$ and $37 \pm 20 \%$ respectively.

We have shown that noise is a significant problem, and that first and second heart sounds can be identified automatically with $58 \%$ success.
\end{abstract}

\section{Introduction}

Phonocardiography using a stethoscope is a very common clinical test, either in hospitals or in family doctor clinics. It can be a valuable diagnostic test for assessing the functioning of the heart valves, where each sound has a normal short crisp characteristic. These sounds change with valve disease. In addition, if the aortic valve is narrowed by disease or calcification an abnormally high sound level due to blood flow can be
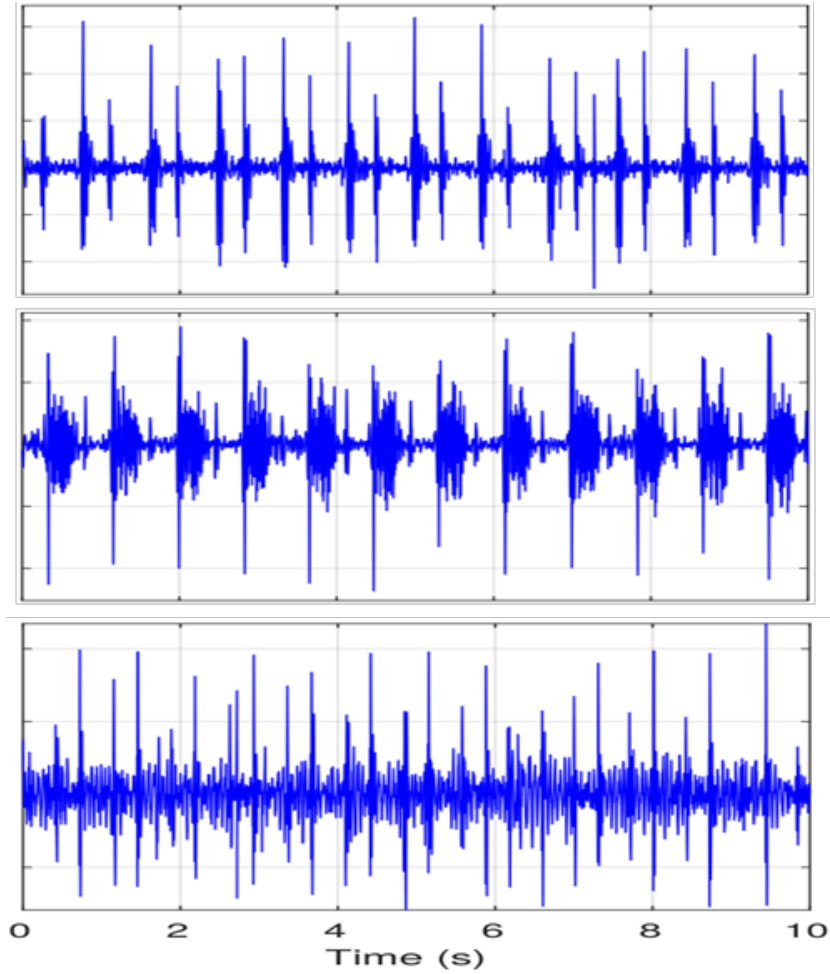

Figure 1. Examples: top - normal phonocardiogram; middle - abnormal phonocardiogram; bottom - noisy waveform, difficult to analyse.

detected while the aortic valve is open.

However, this test is still almost entirely manual using a stethoscope because of the difficulties in analysing waveforms with extra acoustic noise generated due to movement of the stethoscope, and with subtle clinical characteristics requiring good hearing for detection.

In the study, phonocardiography data were made available by PhysioNet [1]. Additional details have been provided by Clifford et al and Liu et al [2,3]. We analysed the data to assess the characteristics that related to better detection of normal or abnormal sound characteristics. 


\section{Methods}

The PhysioNet data were made up of 5 data sets, with a total of 3126 phonocardiogram records, identified as a "training set”. Each record had been analysed by experienced clinicians, and identified as normal or abnormal. There were 2495 normal records and 631 abnormal records. Our analysis was performed before the additional classification of "unsure" was introduced.

All data were downloaded from the PhysioNet web site. [1] Analysis was performed offline.

The sequence of our waveform analysis is shown in Figure 2.



Figure 2. Block diagram of data analysis steps.

\subsection{Phonocardiography data}

All phonocardiograph records had been sampled at 2 $\mathrm{kHz}$. Only a single channel was available for each recording. The records varied in length, and so we used 2 seconds from each to capture at least one heart beat.

\subsection{Noise reduction}

A moving average of 200 points, equivalent to $100 \mathrm{~ms}$, was used to remove high frequency noise and also to accentuate the phonocardiography sounds.

\subsection{Comparative signal levels}

The peak amplitude levels in each record were identified, and the 95\% level was taken as the actual peak of each recording, to avoid spurious noise spikes distorting this measurement. The mean absolute signal level was also measured, and the ratio of mean/peak determined, as the ideal for analysis would be a low ratio.

\section{3. $\quad$ First and second heart sounds}

An approximate level of the first and second heart sounds was obtained by autocorrelation, moving the correlation function through 2 seconds of the file to ensure that the function always moved through one heart beat interval. The autocorrelation was obtained using the Matlab function 'autocorr'. For the analysis of signal autocorrelation amplitudes, the most negative value was first determined and the function shifted in amplitude to make this value zero. When the function was displaced in time by a complete heart beat interval an overall signal level was obtained. For the measurement to be acceptable the peak at the beat interval had to be greater than that for the heart sounds. The amplitude of both sounds were calculated as a percentage of the overall signal level.

The autocorrelation also provided time information of the two sounds relative to the heart beat interval. Because of the smoothing inherent in the function, these data were approximate, but did allow comparison.

\section{Results}

\subsection{Comparative signal levels}

The mean signal level across all records, in comparison to the peak valve sounds was high at $45 \pm 15 \%$. (mean \pm SD) There was a tendency for the noise level to be higher in the abnormal recordings, but this was significant only in one of the five PhysioNet databases with a difference of $8 \%(p=0.002)$. It was noted that one database had significantly higher noise levels than the other four.

Data for this analysis are shown in Table 1.

\subsection{First and second heart sounds}

Autocorrelation was used to analyse the processed waveforms, with successful automated detection in 58\% of recordings of peaks associated with both the first and second heart sounds. This was more effective in the normal group with a $5 \%(\mathrm{p}=0.01)$ greater success rate than in the abnormal group. For all the data analysed, there was only one small significant difference between the normal and abnormal groups, and so combined data are reported. The autocorrelation time to the heart beat interval was $0.83 \pm 0.19 \mathrm{~s}$ (mean $\pm \mathrm{SD}$ ). The first and second sounds relative to the heart beat interval had a timing of $37 \pm 6 \%$ and $64 \pm 6 \%$, and an amplitude of $43 \pm 21 \%$ and $37 \pm 20 \%$ respectively.

The data for the normal and abnormal sounds are shown separately in Figure 3, with more detail in Table 2. 
Table 1. Comparative signal level analysis providing mean to peak signal level ratios in all records (no exclusions) in all groups. This ratio provides an estimate of baseline activity, including noise, relative to the heart sound peaks.

\begin{tabular}{|c|c|c|c|c|}
\hline Waveforms & Number & Mean ratio \% & SD ratio \% & $\mathbf{p}$ \\
\hline All & 3126 & 44.7 & 15.2 & \\
\hline All normal & 2495 & 44.5 & 16.1 & \multirow{2}{*}{$\begin{array}{l}0.173 \\
\text { NS }\end{array}$} \\
\hline All abnormal & 631 & 45.4 & 10.9 & \\
\hline Database a normal & 117 & 39.5 & 9.1 & \multirow[t]{2}{*}{0.0021} \\
\hline Database a abnormal & 292 & 42.7 & 10.0 & \\
\hline Database b normal & 386 & 59.4 & 9.2 & \multirow{2}{*}{$\begin{array}{l}0.191 \\
\text { NS }\end{array}$} \\
\hline Database b abnormal & 104 & 58.1 & 8.1 & \\
\hline Database c normal & 7 & 41.5 & 3.6 & \multirow{2}{*}{$\begin{array}{l}0.092 \\
\text { NS }\end{array}$} \\
\hline Database c abnormal & 24 & 48.4 & 10.2 & \\
\hline Database d normal & 27 & 41.7 & 9.51 & \multirow{2}{*}{$\begin{array}{l}0.964 \\
\text { NS }\end{array}$} \\
\hline Database d abnormal & 28 & 41.6 & 6.65 & \\
\hline Database e normal & 1958 & 41.9 & 16.0 & \multirow{2}{*}{$\begin{array}{l}0.52 \\
\text { NS }\end{array}$} \\
\hline Database e abnormal & 183 & 42.7 & 8.7 & \\
\hline
\end{tabular}

Table 2. Comparative analysis of detection of both first and second heart sounds.

\begin{tabular}{|c|c|c|c|c|c|c|}
\hline Waveforms & $\mathbf{N}$ & $\mathrm{N}$ analysed & Mean & SD & SEM & $\mathbf{p}$ \\
\hline All & 3126 & & & & & \\
\hline All normal & 2495 & 1480.(59\%) & & & & \\
\hline All abnormal & 631 & $338(54 \%)$ & & & & \\
\hline All beat interval (s) & 3126 & $1818(54 \%)$ & 0.83 & 0.19 & 0.045 & \\
\hline $\begin{array}{l}\text { All 1st peak time } \\
\text { (\% of beat interval) }\end{array}$ & 3126 & 1818 & 36.7 & 6.4 & 0.15 & \\
\hline $\begin{array}{l}\text { Normal 1st peak time } \\
\text { (\% of beat interval) }\end{array}$ & 2495 & 1480 & 36.7 & 6.3 & 0.16 & \multirow[t]{2}{*}{$\begin{array}{l}0.438 \\
\text { NS }\end{array}$} \\
\hline $\begin{array}{l}\text { Abnormal 1st peak time } \\
\text { (\% of beat interval) }\end{array}$ & 631 & 338 & 36.4 & 6.9 & 0.38 & \\
\hline $\begin{array}{l}\text { All 1st peak / beat interval } \\
\text { peak amplitude ratio (\%) }\end{array}$ & 3126 & 1818 & 43.3 & 20.7 & 0.49 & \\
\hline $\begin{array}{l}\text { Normal 1st peak / beat } \\
\text { interval amplitude ratio (\%) }\end{array}$ & 2495 & 1480 & 42.9 & 20.8 & 0.5 & \multirow[t]{2}{*}{0.045} \\
\hline $\begin{array}{l}\text { Abnormal 1st peak / beat } \\
\text { interval amplitude ratio (\%) }\end{array}$ & 631 & 338 & 45.4 & 20.3 & 1.1 & \\
\hline $\begin{array}{l}\text { All 2nd peak time } \\
\text { (\% of beat interval) }\end{array}$ & 3126 & 1818 & 64.5 & 6.3 & 0.15 & \\
\hline $\begin{array}{l}\text { Normal 2nd peak time } \\
\text { (\% of beat interval) }\end{array}$ & 2495 & 1480 & 64.4 & 6.1 & 0.16 & \multirow[t]{2}{*}{$\begin{array}{l}0.114 \\
\text { NS }\end{array}$} \\
\hline $\begin{array}{l}\text { Abnormal 2nd peak time } \\
\text { (\% of beat interval) }\end{array}$ & 631 & 338 & 65.0 & 7.1 & 0.38 & \\
\hline $\begin{array}{l}\text { All 2nd peak / beat interval } \\
\text { amplitude ratio (\%) }\end{array}$ & 3126 & 1818 & 37.4 & 20.0 & 0.47 & \\
\hline $\begin{array}{l}\text { Normal 2nd peak / beat } \\
\text { interval amplitude ratio (\%) }\end{array}$ & 2495 & 1480 & 36.8 & 20.1 & 0.52 & \multirow[t]{2}{*}{$\begin{array}{l}0.067 \\
\text { NS }\end{array}$} \\
\hline $\begin{array}{l}\text { Abnormal 2nd peak / beat } \\
\text { interval amplitude ratio (\%) }\end{array}$ & 631 & 338 & 39.0 & 19.3 & 1.1 & \\
\hline
\end{tabular}




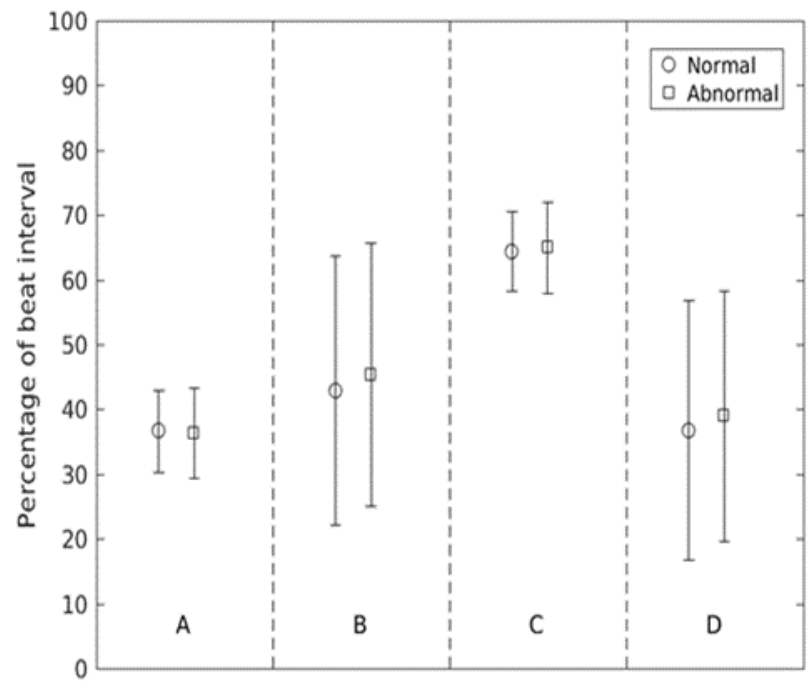

Figure 3. Data analysis for the normal and abnormal records. Mean \pm SD shown. All data are calculated relative to the beat interval data, either for amplitude or timing.

A First sound peak time

B First sound peak amplitude $(\mathrm{P}=0.045)$

C Second sound peak time

D Second sound peak amplitude

\section{Discussion and conclusion}

The noise level was high, as indicated by the high mean-to-peak amplitude level of $45 \%$. This makes the analysis difficult and explains to some extent the poor success in finding characteristics that separate the two groups.

However, we have shown that first and second heart sounds can be identified automatically with $58 \%$ success. This indicated some potential for future automated analysis.

\section{Acknowledgement}

We acknowledge the contribution made by all those who worked hard to create the Challenge.

\section{References}

[1] Classification of normal/abnormal heart sound recordings: the PhysioNet/Computing in Cardiology Challenge 2016. http://physionet.org/challenge/2016/

[2] Clifford GD, Liu C, Springer D, Moody B, Li Q, Abad R, Millet J, Silva I, Johnson A, Mark RG. Classification of normal/abnormal heart sound recordings: the PhysioNet/Computing in Cardiology Challenge 2016. Computing in Cardiology 2016;43. (in press)

[3] An Open Access database for the evaluation of heart sound algorithms. Liu C, Springer D, Li Q, Moody B, Abad RJ, Chorro FJ, Castells F, Millet Roig J, Silva I, Johnson AEW, Syed Z, Schmidt SE, Papadaniil CD, Hadjileontiadis L, Naseri H, Moukadem A, Dieterlen A, Brandt C, Tang H, Samieinasab M, Samieinasab MR, Sameni R, Mark RG, Clifford GD. Physiological Measurement 2016;37. (in press)

Address for correspondence.

Professor Alan Murray

School of Electrical and Electronic Engineering, and Faculty of Medical Sciences, Newcastle University, Newcastle upon Tyne, UK.

alan.murray@ncl.ac.uk 